\title{
A Cross-Sectional Analysis Of Potential Stressors Leading to Depression Among Medical Students of Public Sector Universities of Sindh

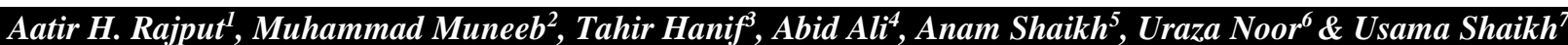

Liaquat University Hospital

LUMHS Research Forum

Sir Cowasjee Jehangir Institute of Psychiatry

Liaquat University of Medical \& Health Sciences, Jamshoro

Combined Military Hospital (C.M.H.), Hyderabad

Corresponding email: aatirh.rajput@gmail.com

\begin{abstract}
Background: Till the 70's, it was believed that depression among students was rare or even non-existent. This concept has now begun to change. Research studies that show presence of depressive problems in students have started surfacing but much more need to be explored. Objective: To find out the causes and level of stress and depression among undergraduate medical students of public sector medical universities and medical colleges of Sindh. Methods: This cross sectional psycho-social analysis included 587 undergraduate medical students from 6 public sector medical institutes of Sindh. Multistage sampling was implemented. Sampling procedure includes both stratified sampling and simple random sampling. Stratification was done on the basis of location of university and medical college and year of study. Informed consent was taken from every student. Stress and depression levels were measured in accordance to academic and non-academic stressors. Data analysis was done on SPSS version 17.0. Results: Girls showed a much higher depression score in comparison with boys. Hostilities had a significantly greater depression score than those who were living with their families. It was revealed that students having higher grades and GPA had much higher scores of depression compared to students having lower grades and GPA. Fear of unemployment after studies and lack of positive response from parents and institution were few of the most potent stressors. Conclusion: On the basis of our result we conclude that a decrease in medical syllabus and time extension in semesters may directly reduce students' workload and consequently decrease the depression level. Stress management programs should be conducted in every institute for coping with the stress. Efficacious moral and substantial support from faculty, teachers and families is crucial to ameliorate of students' health.
\end{abstract}

\section{Keywords}

Stress, Depression and medical students.

\section{Introduction}

Although there are many case studies on depression since the $17^{\text {th }}$ century but scientific interest on depression among medical students is developed recently. The aim of medical education is to get knowledge, to be a highly skilled, competent and a professional physician who is equipped enough to care for the nation's illness, who proceeds advancement in field of medicine, and public health. Depending on these particular characteristics, one may anticipate a medical institute would be a time of personal growth, demand, and a great source of stress and depression. Till the 70's, it was believed that depression among students was rare or even nonexistent (Maria A. et al, 2013; Besseghini VH, 1997). This concept has now begun to change. Research studies that proved presence of depressive problems in students have also suggested changes in this conception. Major depression (MD) in students is commonest, debilitating and recurrent type of depression that involves a high degree of morbidity and mortality and it is a great public health concern, although still often not diagnosed nor much treated. Several studies noticed the phenomenon of depression in students has been occurring more frequently and earlier than before. But there are some epidemiological studies about depression at this period of life (Maria A. et al, 2013; Mirza KAH. et al, 1996)

Epidemiological studies about depression and depressive symptoms in students have shown differences of occurrence, in the different rates of the specific age groups and in the gender distribution. A rise in occurrence of depression and depressive symptoms during teenage has been accepted widely, 
but the exact time or age in which it happens is still not clearly known. It is also not found yet whether there are high chances of predominantly depressive symptoms associated with age and gender differences or not (Maria A. et al, 2013; Mirza KAH. et al, 1996).

Stress is usually defined as any unusual need of a body based on one's internal or external resources that makes a person to utilize more energy reserves in excess of what would be necessary for dealing with ordinary life events. Signs of being stressed can be demonstrated through observable behaviors such as tremors or tics, thumb or finger sucking, nail biting, hair twirling, helplessness, physical hostility, complaints of physical aches and pains, irritability, nervous laughter, outbursts, crying, and withdrawal. Stress affects most people in some way. Acute stress causes rapidly change along whole body. Almost all biological systems of the body like circulatory system, immune system, respiratory, digestive system, sensory organs, and nervous system, are accelerated efficiently to cope with upcoming danger. Chronic stress can have serious effects on one's health and it should be treated like any other health concern in order to get a sound physically and psychologically fit individual. (Roberts RE. et al, 1995)

Medical institutes demand more academic and clinical knowledge and to cope up with this, students' working hours into nights and weekends, are much extended ${ }^{[1]}$. A number of sources of stress are frequent examinations, exam phobia, time limits, reduced leisure time, an over demanding curriculum, complicated treatments, possible conflicts with patients, fellow students, institution staff and faculty, lack of self-esteem, and most important the differences between the student's expectations and reality. (Rajab L, 2001)

Based on the current literature and scientific studies on depression and stress among students, I strongly consider that medical students among all have greatest risks of depression and depressive symptoms because of the increasing needs and challenges of the medical profession related to both quality and quantity of academic and clinical performance. This study proves that a change is strongly needed in curriculum planning and working environment of medical institutions. Academic as well as nonacademic sources of stress should be minimized. Furthermore, effective communication and assistance from faculty, administration and families is essential in order to get better results from students.

\section{Methodology}

This cross sectional multi-center study was designed to get a complete picture of the prevalence of stress and depression among undergraduate medical students of public sector medical colleges and universities of Sindh, namely Dow Medical College, Karachi, Sindh Medical College, Karachi, Liaquat University Of Medical \& Health Sciences, Jamshoro, Peoples University Of Medical \& Health Sciences For Women Shaheed Benazirabad, Chandka Medical College, Larkana And Ghulam Mohammad Maher Medical College, Sukkur, and to find out the causes, perceptions and preventive measures for stress and depression. 587 undergraduate medical students both male and female took participation in the study. Multistage sampling was implemented and equal numbers of questionnaires were assigned to each public sector medical university or college of Sindh. Sampling procedure includes both stratified sampling and simple random sampling. Stratification was done on the basis of location of university and medical college (being public sector university is foremost decisive factor), and year of study. 20 questionnaires were assigned to each studying year and further sampling procedure was conducted according to simple random sampling. Every $17^{\text {th }}$ student according to call roll number was selected for the study. A prerequisite informed consent was taken from every student. A semi quantitative questionnaire based on Hamilton scale of depression for adults was designed, having full information of demographic bio data and information about financial status, place of residence (hostel or home) and life luxuries. Other questions were about duration of study in normal days and during exams, number of assignments and tests, number and types of recreational activities occurring in institutions and type of hobby and time given to it, were also asked from every participant. Data collection took three and half month, started from $10^{\text {th }}$ of February, 2014 to $26^{\text {th }}$ of May, 2014 and Data processing and analysis was done by using SPSS version 17.0. Total duration of study was 6 months i.e. from $15^{\text {th }}$ of January, 2014 to $15^{\text {th }}$ of June, 2014.

\section{Results}

A total of 600 questionnaires were administered to both male and female undergraduate medical students by using multistage sampling procedure (100 to each Public Sector University or medical college) out of which 587 (98\%) questionnaires was returned. Out of which $64.05 \%$ (376) were girls and $35.95 \%$ ( 211) were boys. Mean age was 20.13 while standard deviation was found to be of +1.73 . 
grades and GPA had much higher scores of

As in general, girls showed much higher depression score (22.76) in comparison with boys (20.34). Combine depression score of all undergraduate medical students was 21.67. Hostilities had significant depression score i.e. 21.35 than those who were living with their families i.e. 19.28.

Massive syllabus, day to day assignments, weekly and monthly tests and lack of recreational activities among students had highly overburdened them. It can be assumed by the study that students having higher depression compared to students having lower grades and GPA. The divergence in observed problems among public sector medical colleges and universities of Sindh were investigated.

Trouble in getting good study material, poor time management and fear of parents in case of being failed, were reported as main stressors by the students. Fear of unemployment after studies and lack of positive response from parents and institution had significantly raised stress and depression among students.

Gender Distribution Among Medical Students

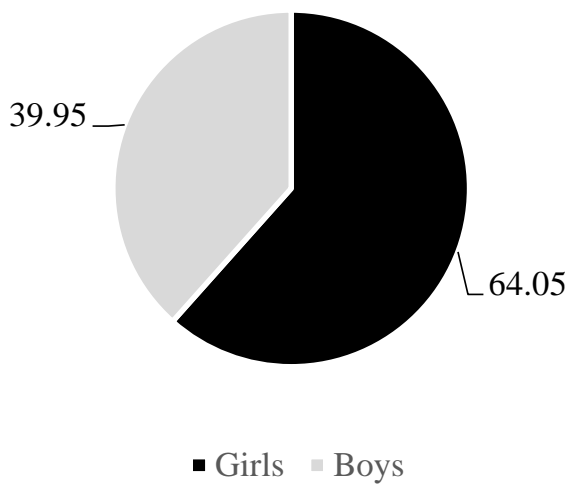

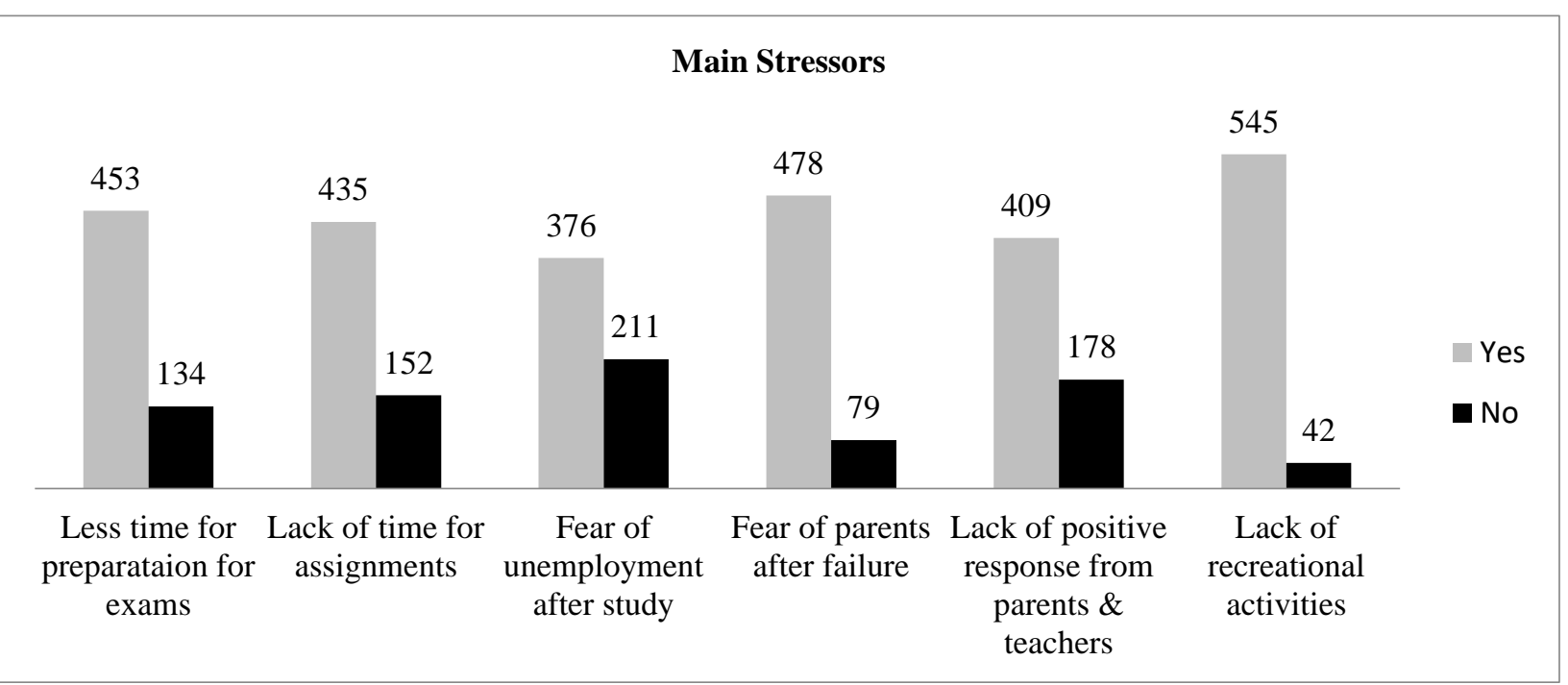


Mean Depression Score

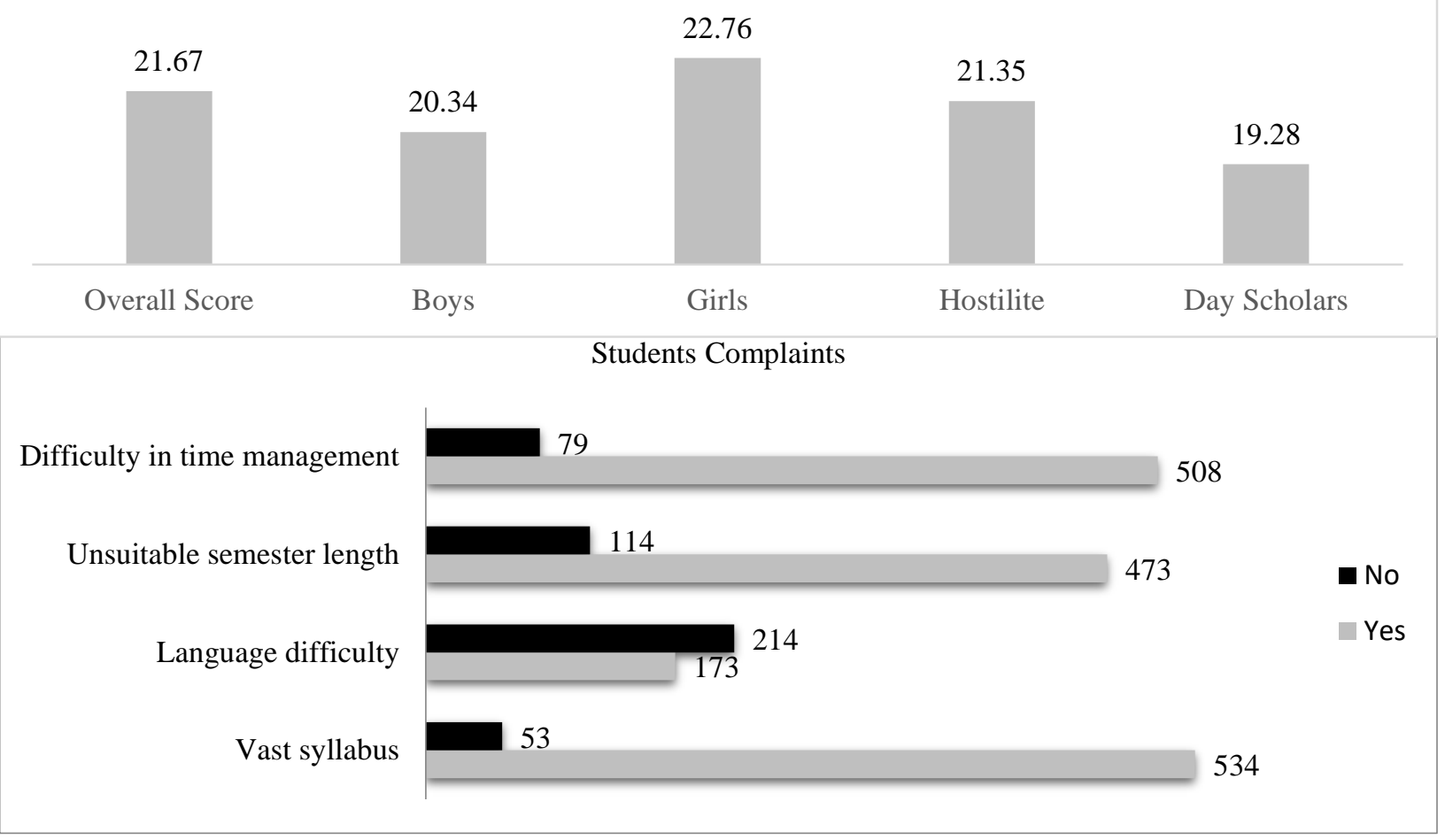

\section{Discussion}

Studies revealed that unskilled students have always been vulnerable to many stressful situations in their life, especially in pursuing of their professional education in much competitive environment. Students suffered from depression at least once or more during the course of their professional education. Being most needy, challenging and stressful learning places (Polychronopoulos A. et al, 2005) medical institutions are greatly renowned.

Studies suggested that a considerable portion of medical students' i.e. $15-26 \%$ had been suffering from one or other kind of emotional disturbance and they were seriously in need of prompt treatment (Jenny F, 1986; Pitts FN. et al, 1961). It is evident that the duration of stress is of much worth and there is a decrease in stress with advancing year of medical training (Adsett CA, 1968).

Spotting out of significant problems is of much importance in medical programs as it may give students and faculty an opportunity to take preventive measures for stress (Yap. et al, 1996). This can be proven by the fact that majority of medical students are not well adopted to the educational environment and to the workload imposed by the medical institution which leads to higher levels of stress and depression (Bradley I. et al, 1989). Higher levels of psychiatric illness in medical students were found during a study in US when compared with general population. More than $20 \%$ of medical students met diagnostic criteria for psychiatric illness (Lloyd C. et al, 1984). A number of studies have demonstrated the relation between stress concept in regards or several factors like gender, marital status, professional courses, academic year, living environment, and socio-cultural factors that affects student's mental health (Polychronopoulos A. et al, 2005; Yap A. et al, 1996; Tedesco LA, 1986; Tedesco LA. et al, 1987; Grandy T. et al, 1989; Westerman G. et al, 1993; Heath JR. et al, 1999).

Studies also suggest a higher prevalence rate of depression in women than in men. (Adsett CA, 1968; Yap. et al, 1996; Bradley I. et al, 1989; Lloyd C. et al, 1984; Tedesco LA, 1986; Tedesco LA. et al, 1987; Grandy T. et al, 1989; Westerman G. et al, 1993; Heath JR. et al, 1999). Although there are not much studies that shows discrimination factor among male and female students but the fact that female doctors who are doing postgraduate training have noticeably higher rates of mental health problem than male 
doctors is revealed by some researchers. (Borrill CS. et al, 1996)

Modern educational systems have been a cause of increase prevalence of stress, anxiety and depression among medical students, suggested by a number of studies (Ball S. et al, 2002; Tyssen R. et al, 2001). Furthermore it is also evident that mental distress among doctors in practice (Gelfand DV. et al, 2004) has its roots somewhere in medical school (Tedesco LA. et al, 1986). It is also suggested that the practice of medicine either by qualified physicians (Vincent MO, 1983) or medical students (Pitts FN. et al, 1961) produces risks to mental health and the link between medical training and mental health problems have also been suggested (Reibord SP, 1983). Majority of research presented seconds the presence of a relation among stress and depressive episodes, based on sporadic stress causing agents that have an annoying and unwanted content. Generally, these agents affect both psychological and physical health of student but some studies also suggest the direct effects of these agents that create hazardous-stress-harmful pathway.

An epidemiological study stated that non respondents to questionnaires were supposed to be more depressed than respondents (Vernon SW. et al, 1984) but the response rate of my study (98\%) in comparison with previous studies particularly makes its finding worth important and it can be applicable to all medical students. A total of 687 undergraduate medical students belonging 7 public sector medical institutions of Sindh have been surveyed in this study which shows the differences in observed problems and hence their stress and depression level. Students coming from Cambridge level system (had studied in 'A' levels) showed much less academic and clinical problems in comparison with the students coming from higher secondary college system (intermediate system).

It is found that students having low grades and GPA have statistically significant greater number observed problems than that of students with high grades and GPA in overall depression score. This is rational to results of other studies which similarly showed same results that low satisfaction rate of students with their educational environment characteristically causes low academic achievements (Mayya SS et al, 2004). Fear of talking to patients, improper handling and consoling and following up of proper treatment was a major source of stress as reported by most of students. Clinical practice being most valued one has undoubtedly as its leading role in developing stress and depression in students. Monthly tests and assignments have also significant role in shattering of mental health of students.

Third most reported cause of depression is the communication and coordination gap between students and faculty. Students living at hostel have less depression rate as compared to those living with families. High depression score for student- faculty relationship and clinical training is typically found in students living with their families. The probable causes of which are increasing demands of social activities that overburdened student and limit time as well. Students those who are disgraced by the teachers in front of their class fellows tend to show more depressive symptoms. Feeling of frustration and powerlessness was rate highest on stress incident record while tension and anxiety- surprisingly were on second grade. These feeling may become an imminent part of medical students' nature and they significantly contribute to experience of the 'learned helplessness' that is eventually associated with depression. (Jenny F, 1986; Mayya SS et al, 2004).

Medical institutions are becoming more demanding: academic and clinical training now require more working hours. Examination fear, day to day tests and assignments, short preparation leaves, strenuous curricula, clinical training, anxious and conflicted patients, complicated treatment, difficult procedures and follow-ups, fellow colleagues, staff and faculty, lack of recreational activities and lack of selfconfidence and self-esteem are typical sources of stress for medical students. With Proper counseling (Mc Auliffe WE. et al, 1984) and support from teachers (Jenny F, 1986; Filed D, 1984) a marked reduction in depression levels among medical students can be made possible which will surely result in more, better and efficacious output by medical students and in broad sense it will ultimately be the society that will have maximum benefits.

\section{Conclusion}

Strenuous and limitless syllabus of medical profession was found to be the major source of depression. Conventional methods of teaching, clinical training, fear of patients and lack of studentfaculty relationship were important unanswered matters. A lessen in medical syllabus, a bit time extension in semester may directly reduce students' workload and indirectly reduces the depression level. It is a recommendation that by up gradation and modification of clinical training system may contribute significant reduction in observed problems of students. This study confirms the fact that needs of medical profession related to both quality and

Aatir H. Rajput 
quantity of academic and clinical practice are important sources of stress.

The sources of stress both academic and clinical must be considered in planning of curricula. Working environment, student-faculty relationship and syllabus length should be upgraded and modified for betterment of students' mental health. Stress management programs should be conducted in every institute for coping with the stress. In the last but not the least efficacious moral and substantial support from faculty, teachers and families is crucial for amelioration of students' health.

\section{Conflict of interest}

All the authors disclosed that there is no conflict of interest associated in the preparation of this article.

\section{Acknowledgements}

We would like to acknowledge the intellectual assistance and technical support provided by LUMHS Research Forum

\section{Reference}

- Adsett CA. (1968). Psychological health of medical students in relation to the medical education process. J Med Educ. 43 (6), 697-699.

- Ball S, Bax A. (2002). Self-care in medical education: effectiveness of health-habits interventions for first-year medical students. Acad Med. 77, 911-917.

- Besseghini VH. (1997). Depression and suicide in children and adolescents. Ann $N$ York Acad Scie. 816, 94-98.

- Borrill CS, Wall MA, West GE, et al. (1996). Mental Health of the Workforce in NHS Trusts. Final Report. Sheffield: Institute of Work Psychology, University of Sheffield/Leeds: Department of Psychology, University of Leeds.

- Bradley I., Clark C., Eisner J., DeGruchy K., Singer D.,Hinkleman K., et al. (1989). The student survey of problems in the academic environment in Canadian dental faculties. J. Dent. Educ. 53, 126-131.

- Field D. (1984). Formal instruction in United Kingdom medical schools about death and dying. Med Educ. 18, 429-34.

- Gelfand DV, Podnos YD, Carmichael JC, Saltzman DJ, Wilson SE, Williams RA. (2004). Effect of the 80-hour workweek on resident burnout. Arch Surg. 139, 933-940.

- Grandy T., Westerman G., Erskineombs C., (1989). Turner C. Perceptions of stress among third-year dental students. J. Dent. Educ. 53, 718721.
- Heath J.R., Mcfarlane T.V., Umar M.S. (1999). Perceived sources of stress in dental students. Dent. Update. 26, 94-100.

- Jenny F. (1986). Levels and sources of stress in medical students. British medical journal. 292-93.

- Lloyd C, Gartrell NK. (1984). Psychiatric symptoms in medical students. Compr Psychiatry. 25, 552-565.

- Maria A, Kisaf A, Salman Z, Rabia S, Ahsan I, Mohammad O. et al. (2013). Medical students bearing mental stress due to their academic schedule. IJEHSR. 1 (2), 93-97.

- Mayya S.S., Roff S. (2004). Students' perceptions of educational environment: a comparison of academic achievers and underachievers at Kasturba Medical College, India. Educ. Health. 17, 280-291.

- McAuliffe WE, Rohman M, Wechsler H. (1984). Alcohol, substance use and other risk-factors of impairment in a sample of physicians-in-training. Advances in Alcohol and Substance Abuse. 4, 6787.

- Mirza KAH, Michael A. (1996). Major depression in children and adolescents. Br J Hosp Med. 55, 57-61.

- Pitts FN, Winokur, G, Stewart MA. (1961). Psychotic syndromes, anxiety symptoms, and response to stress in medical students. Am J Psychiatry. 118, 333-340.

- Pitts FN, Winokur, G, Stewart MA. (1961). Psychotic syndromes, anxiety symptoms, and response to stress in medical students. Am J Psychiany. 11 (118), 333-40.

- Polychronopoulos A., Divaris, K. (2005). Perceived sources of stress among Greek dental students. J. Dent. Educ. 69, 687-692.

- Rajab, L. (2001). Perceived sources of stress among dental students at the University of Jordan. J. Dent. Educ. 65: 232-241.

- Reibord SP. (1983). Psychological perspectives on iatrogenic physician impairment. Pharos. 2-8

- Roberts RE, Chen Y-W. (1995). Depressive symptoms and suicidal ideation among Mexicanorigin and anglo adolescents. J Am Acad Chaild Adolesc Psychiatry. 34, 81-90.

- Tedesco L.A. (1986). A psychological perspective on the dental education experience and student performance. J. Dent. Educ. 50, 601-605.

- Tedesco, L.A. (1986). The etiology of survival: a psychological perspective on the dental school experience. In: Paper presented at the American Association of Dental Schools Annual Meeting, Washington DC. 
- Tedesco, L.A., Flatow E., Davis E.L., Brewer J.D., Cooper M.L. (1987). Performance and psychosocial response to the dental school educational experience: exploring barriers to learning. In: Paper presented at the American Association of Dental School Annual Meeting, Chicago.

- Tyssen R, Vaglum P, Gronvold NT, Ekeberg O. (2001). Suicidal ideation among medical students and young physicians: a nationwide and prospective study of prevalence and predictors. $J$ Affect Disord. 64, 69-79.
- Vernon SW, Roberts RE, Lees ES. (1984). Ethnic participation in longitudinal health studies. Am J Epidemiol. 119, 99-113.

- Vincent MO. (1983). Some sequelae of stress in physicians. Psychiar J Univ Otawa. 8, 120-124.

- Westerman G., Grandy T., Ocanto R., Erskine C. (1993). Perceived sources of stress in the dental school environment. J. Dent. Educ. 57, 225-231.

- Yap, A., Bhole, S., Teo, C. (1996). A crosscultural comparison of perceived sources of stress in the dental school environment. J. Dent. Educ. 60, 459-464. 